EMPIRICAL STUDIES OF THE ARTS, Vol. 26(1) 5-13, 2008

\title{
CREATIVITY AND E-ADVERTISING: A QUALITATIVE STUDY OF ART DIRECTORS' CREATIVE PROCESSES
}

\author{
MARIE-PIERRE FOURQUET-COURBET \\ Institut Universitaire de Technologie \\ University of Avignon et des Pays de Vaucluse, France \\ DIDIER COURBET \\ Institut Universitaire de Technologie \\ University of Aix-Narseille 2, France \\ MARC VANHUELE \\ HEC School of Management, Paris, France
}

\begin{abstract}
An interpretive analysis of qualitative interviews with 33 creators of advertising banners for the Internet, combined with retrospective protocols on the creation process, reveals that they hold implicit theories about the potential impact of their work on different audiences. These audiences intervene in the form of intraindividual imaginary dialogue partners who, throughout the creative process, give their reactions to the message being created. Creation and evaluation are therefore intertwined and not, as the literature on creativity has suggested, two sequential steps of the creative process.
\end{abstract}

Since the beginning of the past century, several areas of aesthetic research have examined advertising. Most research has focused on the finished product (i.e., the message), and little of it has studied the production process and the creative activity of art directors and copywriters. Recent research on creativity, inspired by applied social and cognitive psychology (e.g., Lonergan, Scott, \& Mumford, 2004; Mumford, 2003) has, however, motivated a renewed interest in this topic.

(c) 2008, Baywood Publishing Co., Inc. doi: 10.2190/EM.26.1.b

http://baywood.com 
If creativity has been examined in various areas of aesthetic research (Feist, 1999; Locher, Martindale, \& Dorfman, 2006; Sternberg, 1999, 2006), research on creativity in e-advertising has yet to be published. It is not clear to what extent creativity in e-advertising and in large media advertising are similar. On the one hand, the gradual increase in the use of the Internet has enabled a renewal of advertising creativity because this new medium offers new creative applications like, for instance, interactivity and hypertext links that are not present in traditional media. On the other hand, e-advertisers seem to impose more social, aesthetic, and economic constraints on their creations than do traditional advertisers. Art directors and copywriters in the e-advertising world may therefore follow different, maybe more constrained, creative processes. We examine these processes based on in-depth interviews with the creative actors and compare the results to those observed in traditional advertising.

The overall objective of our research is to study empirically how practitioners (art directors, copywriters and web designers) create web banners. We follow an inductive approach, building on the results of qualitative interviews with these practitioners, combined with retrospective protocols on the creation process. As background for our analysis, we especially used the work of Kover (1995), who showed that communication creatives in traditional media work without support from formal and scientific theories of communication but, instead, share implicit theories.

Our first specific objective was to gain an understanding of the implicit representations and theories that web banner designers hold to create their message. We addressed the following questions. How are these theories organized? What is the place of the target audience in these implicit theories? What are the functions of the aesthetic and semiotic Internet systems in these theories? The second objective of our work was to examine in more detail how the intraindividual creative process of web designers is linked to the process of evaluation that follows the creative activity as such. This evaluation process has been neglected for a long time in research on creative thinking. A third specific objective was to verify the existence of the "creative trance" that Kover (1995) diagnosed during the creation of the advertising messages in traditional media. During this creative trance, copywriters engage in a discourse with the internalized ideal viewer. Do these internal dialogues exist in web banner creation? If so, how do they occur? What are the functions of these intrapsychic dialogues in the process of evaluation of the banner ad as it is taking form?

\section{METHOD}

\section{Participants}

Thirty-three French web banner designers volunteered to serve as participants. The web designer world is young and may not yet have a strongly developed culture. In France, the profession has only started to take shape since 1999. So we can see that all our informants have 2 to 5 year's experience in e-advertising 
creation. Furthermore, web banner designers are a very heterogeneous group. Therefore, we attempted, in our sample selection, to maximize the diversity of profiles of our informants in terms of work environment (advertising agency $36 \%$, Internet oriented agency $-33 \%$, graphical design agency $-24 \%$ ) and previous work experience (traditional advertising creatives $-30 \%$, traditional graphical designers $-18 \%$, web designers $-15 \%$, computer experts $-15 \%$, graphical computer designers $-15 \%)$.

\section{Procedure}

A qualitative approach is the most suitable to get in-depth insights into the creative process (Russ, 2003). We interviewed the 33 web banner designers using a face-to-face semi-direct format with open questions. We combined this type of interviewing with retrospective protocols on the creation process. Designers were asked to show past creations on the computer screen and to explain step-by-step how they had developed them by thinking out loud.

The aim of our analysis was to identify shared views of the creative process (and not the differences in responses across informants) by using a hermeneutic perspective. After filtering out irrelevant information in the collected speech, the interview transcripts (1,530 interventions and 69,007 words) were analyzed independently by two coders. After a first reading of all the transcripts, content analysis was used to assign the text data to mutually exclusive categories, representing themes and sub-themes (Smith, 2000; Spiggle, 1994). This assignment was constantly updated and revised, new categories were added, some were aggregated and other ones deleted. Once the categorization of each individual coder had stabilized, the results of the two content analyses were compared. The intercoder agreement on the coding into themes was $85 \%$. Disagreements were resolved after discussion. The resulting themes are listed in Appendix 1. The saturation point (Glaser \& Strauss, 1967, pp. 61-62) for the analysis was obtained at the 25th interview. From the 26th interview onwards no new information was discovered, which indicates that our sample size was largely sufficient for this qualitative study. We evaluated 1) the relative importance of each theme and sub-theme compared to the whole corpus, and 2) the importance of each sub-theme compared to the topic to which it is attached. The main results are summarized in this article in the form of three theoretical contributions that constitute the next three sections. We illustrate our findings with representative excerpts from the interviews.

\section{RESULTS AND DISCUSSION}

\section{Five Imaginary Dialogues}

Like copywriters, web banner designers hear intra-psychic voices and engage in dialogues in working memory with these voices. These processes of imaginary 
interaction are directed by the voice of the designer's ego in the course of creation, but this ego does not feel in control and, instead, feels absorbed by this process ("I am in another world, do not feel time passing and do not know where I am."). During this phase of "creative trance," web designers dialogue not only with an imaginary viewer, but with four additional intrapsychic voices representing internalized actors.

Like Kover (1995) who refers to the imaginary viewer as "an internalized target person" (p. 601), the first voice the designer hears is that of the recipient surfing the Internet who reacts to the message being created. The designer can consider himself to be the referent; he then dissociates his own self in two and dialogues with another self who plays the role of the typical recipient of the web banner ad. He can also create a recipient built from his mental representation of the typical individual. The second voice is that of the advertiser. The designer imagines what the advertiser would say about the designed banner ads and does this on the basis of information received during the briefing, the objectives of the campaign and knowledge of competitive banner advertising activity ("Suddenly I hear the advertiser shout that I am a no-good, that I do not understand what he wants").

The ego of the people interviewed also interacts with two imaginary colleagues. The first colleague incarnates an excellent banner ad designer who represents the standards and practices in the profession. Interaction with this fellow member of the design community permits an evaluation of the value of the choice options in design. The second colleague knows perfectly the latest fashions and recent trends in the field of advertising creation on the Internet. Professional colleagues are an important target audience for creatives and we notice that they are already present in mind during the creation process itself. The interviews indicate that the opinions of the two imaginary fellow members are mentally created from a continuous monitoring of Internet advertising.

Finally, the fifth voice incarnates the aspirational self-image of the designer (by a principle of "psychic dissociation of ego"). This is the image that the designer hopes others will hold of him or her and that will give him or her a unique position in the world of banner designers ("Whenever possible, I try to make advertisements that are light, nice or humorous"). Taken together, we observe that our informants feel the need to connect with several others and get positive reactions from all. This implies that compromises have to be made and that tension usually remains present even if the best possible solution has been found ("It is rare that all those I imagine agree. But I have to make sure that at least three of four are not frustrated").

\section{Shared Implicit Theories}

Implicit theories are based on social interpretations of reality shared by a group (Moscovici, 1984). Even if they are not scientifically founded and if people often 
cannot express them in a precise way, these theories are used by individuals to explain reality. The communication objectives of web designers are different from those of copywriters; they attempt most often to generate click-throughs to the website of the brand. Nevertheless, our results indicate that web banner designers share the same implicit theories of the communication process as traditional copywriters.

They refer to the same serial process of reception and influence of the message as that discovered for traditional advertising, following a hierarchy of cognitive and affective steps. We also observed that web designers allocate specific functions in this process to the various aesthetic and semiotic systems they conceive (Fourquet-Courbet, 2004).

As a first step, they try to draw the attention of the net surfer. Designers often rely on animation or unexpected and incongruous messages for this step. To create animation, they use a mix of visual techniques (flickering, the alternation of moving and motionless elements, contrasts of colors, forms and typographies). However, designers have to be cautious because too much animation seems to be harmful to the message. To create a visual surprise, designers rely on a specific graphical atmosphere, creative codes out of the semantic universe of the product or more traditional approaches (originality, playfulness, teasing, etc.). Their objective is often to generate positive emotions to make the receiver more open to the message itself. The communication rules that designers refer to often seem to have a universal character for them; they apply in all situations, for all audiences and products (e.g., "flickering attracts the viewer's attention").

As soon as the imaginary recipient has allotted attention to the message, the designer will try to make him understand the content (second stage). In order to go successfully through this stage, the message must be simple at the formal level (e.g., have the right typography) and explicit on the semantic level (coherence between text and image). In spite of the strong level of iconicity of advertising on the Internet, understanding is, according to our informants, primarily generated by the text.

According to our informants, once Internet users have understood the message, they move to the third stage: the memorization of the message. To facilitate memorization, the key elements of the message are immediately emphasized (e.g., with colors that are easily remembered, usage of the well-known style of the advertiser, visual shifts, funny images) and also repeated within the same banner ad or in different banner ads. Moreover, the text must be clear, simple and directly linked to the product (Courbet \& Fourquet-Courbet, 2005).

The last stage is the click of the banner. According to our informants, every element of the creation (e.g., its originality on the home page of the web site or its simplicity) can make the click easier. To encourage the net surfer to click on the banner they use creative techniques that draw attention (e.g., intriguing him with an amazing offer, shocking images, a game and the lure of money, a teaser, using words that facilitate the click like "free" and "reduced prices") but that 
also can mislead him (e.g., copying the graphical environment of Microsoft Windows). This last proposition seems to be controversial because, at the same time, it is recommended to reassure the Net Surfer and to inspire him with confidence.

\section{The Evaluation Phase in the Creative Process}

The majority of academic work on the process of creativity (e.g., El-Murad \& West, 2004; Wallas, 1926) posits that the process of assessment takes place at the end of the act of creation. Our results indicate instead that the process of assessment is iterative and that evaluations are continuous during the creative process. Very early on in the process, evaluation standards are constructed that serve as benchmarks throughout the process. They are not binary (acceptable vs. unacceptable), but rather form a latitude of acceptance and are regularly questioned by the mechanism of "the internal dialogues." When the designer thinks that his creation is close enough to its "ideal-typical banner ad" (Weber, 1949), and is sufficiently accepted by the imaginary dialogue partners, he can stop the design process. The creative evaluation standards will also reappear in the arguments for the final presentation to the advertiser.

Interestingly, web banner designers are either optimistic or pessimistic about the overall impact of their work. Most of the informants think that the Internet has at least as much influence or even more than traditional advertising media (television, radio, press) because it individualizes communication, establishes a privileged relation with the recipient, and is a faster, more interactive and richer multi-sensory medium. These designers sometimes seem to have an exaggerated opinion of the power of their creations because they ignore the other factors that determine the success of their banners (e.g., the product positioning, the attractiveness of the offer, the media plan). Thanks to the "feedback" that Internet allows (number of clicks, sales, site traffic) the designer can quickly assess the quality of the banner ads created and modify them accordingly. Some designers, on the other hand, consider that the influence of web banners is weak. According to them, because the Internet surfer is cognitively more "active" than the recipients of other traditional media, he is also more able to circumvent advertising. This avoidance then stimulates the use of more intrusive forms of web advertising (like "pop-ups") that are considered as potentially harmful for the advertiser, because they obstruct the navigation of the Net surfer who then consciously seeks to avoid them. In addition, it seems that as the recipient gets more experienced, he becomes accustomed to banner advertising whose impact then decreases. In conclusion, we have again observed the presence of implicit theories, here of the effect of communication, that have an influence on the creative activity of web designers. 


\section{APPENDIX 1}

In total, we identified 13 themes that summarized 86 subthemes, that themselves originated from 243 categories. Below we list the themes and give, as illustration, the subthemes for those that are main basis for this article.

1. Origin of the process of creation

i. the role of intuition of the creator

ii. the role of scientific theories

iii. common sense

iv. the influence of experience

v. trends and fashions

vi. creativity as an important aim by itself

vii. the role of the advertiser

viii. no rules, difficult to describe the process

ix. a creative a style, a special "touch"

$\mathrm{x}$. team creativity

2. How creatives perceive their audience

i. particularities of banner reception

ii. profile of the surfer

iii. triggering click-throughs

iv. Internet has a selective audience

3. Evaluation and testing of the creative product

i. the role of acquaintance and the inner circle

ii. testing on oneself

iii. the opinion of the advertiser

iv. technical tests

v. testing on the (imaginary) audience

vi. no testing

vii. the type of testing depends on the type of creation

4. The overall influence of e-advertising

5. Overall rules of creation

6. Attracting attention

7. Maximizing credibility

8. Facilitating understanding

9. Increasing retention in memory

10. Obtaining correct attribution

11. Inciting action

12. Measures of effectiveness

13. Internet compared to other media 


\section{ACKNOWLEDGMENT}

This study was financed by the program "Cognitique, Société de l'Information" of the CNRS (French National Center for Scientific Research).

\section{REFERENCES}

Courbet, D., \& Fourquet-Courbet, M.-P. (2005). Les processus psychologiques lors de la création publicitaire [Psychological process during advertising creativity]. Hermès, 41, 67-74. Paris: Editions du CNRS, France.

El-Murad, J., \& West, D. C. (2004). The definition and measurement of creativity: What do we know? Journal of Advertising Research, 44, 188-201.

Feist, G. J. (1999). The influence of personality on artistic and scientific creativity. In R. J. Sternberg (Ed.), Handbook of creativity (pp. 273-296). Cambridge, MA: Cambridge University Press.

Fourquet-Courbet, M.-P. (2004). Influence attendue et influence effective de la publicité sur Internet. Des représentations sociales des producteurs aux modèles scientifiques [Expected influence and effective influence of Web advertising. From social representations of the producers to scientific models]. Questions de Communication, 5, 31-53. Nancy: Presses Universitaires de Nancy, France.

Glaser, B. G., \& Strauss, A. L. (1967). The discovery of the Grounded Theory: Strategies for qualitative research. New York: Aldine.

Kover, A. J. (1995). Copywriters' implicit theories of communication: An exploration. Journal of Consumer Research, 21(4), 596-611.

Locher P., Martindale C., \& Dorfman, L. (Eds.). (2006). New directions in aesthetics, creativity and the arts. Amityville, NY: Baywood.

Lonergan, D. C., Scott, G. M., \& Mumford, M. D. (2004). Evaluative aspects of creative thought: Effects of appraisal and revision standards. Creativity Research Journal, $16(2 \& 3), 231-246$.

Moscovici, S. (1984). The phenomenon of social representations. In R. Farr \& S. Moscovici (Eds.), Social representations (pp. 113-128). Cambridge, MA: Cambridge University Press.

Mumford, M. D. (2003). Where have we been, where are we going? Talking stock in creativity research. Creativity Research Journal, 15(2\&3), 107-120.

Russ, S. W. (2003). Creativity research: Whither thou goest. Creativity Research Journal, 15(2\&3), 143-145.

Smith, C. P. (2000). Content analysis and narrative analysis. In H. Reis \& C. M. Judd (Eds.), Handbook of research methods in social and personality psychology (pp. 313-335). Cambridge, MA: Cambridge University Press.

Spiggle, S. (1994). Analysis and interpretation of qualitative data in consumer research. Journal of Consumer Research, 21, 194-203.

Sternberg, R. J. (1999). Handbook of creativity. Cambridge, MA: Cambridge University Press.

Sternberg, R. J. (2006). Stalking the elusive creativity quark: Toward a comprehensive theory of creativity. In P. Locher, C. Martindale, \& L. Dorfman (Eds.), New directions in aesthetics, creativity and the arts (pp. 79-104). Amityville, NY: Baywood. 
Wallas, G. (1926). The art of thought. New York: Harcourt Brace.

Weber, M. (1949). The methodology of the social sciences. E. A. Shils \& H. A. Finch (Trans. \& Ed.). New York: The Free Press.

Direct reprint requests to:

Dr. Marie-Pierre Fourquet-Courbet

University of Avignon et des Pays de Vaucluse

EA 3151, IUT d'Avignon

337 chemin des Meinajaries

Site Agroparc. BP 1207

84911 Avignon cedex, France

e-mail: marie-pierre.fourquet@univ-avignon.fr 